\title{
Coordination in Distributed, Self-managing Work Teams: The Roles of Initiated and Received Task Interdependence
}

\author{
Marthe Berntzen \\ University of Oslo \\ Department of Informatics \\ marthenb@ifi.uio.no
}

\author{
Sut I Wong \\ BI Norwegian Business School \\ Department of Communication \\ and Culture \\ sut.i.wong@bi.no
}

\begin{abstract}
While coordination is assumed to contribute to distributed self-managing work team performance, our knowledge about the factors influencing coordination in such team settings is limited. In the present study, we investigate the moderating roles of initiated and received task interdependence on the relationship between self-management and coordination perceptions in distributed teams that rely on electronic communication tools to interact. A field survey study of 110 employees in 40 distributed teams demonstrated that when there are high levels of initiated task interdependence and low levels of received task interdependence, team self-management is associated with stronger perceived coordination in distributed teams. Based on these results, we discuss theoretical and practical implications for distributed self-managing teams.
\end{abstract}

\section{Introduction}

The concept of self-management and self-managing work teams (SMWTs) emerged in the management literature almost half a century ago as a promising tool to foster team coordination, effectiveness and performance $[31,33]$. SMWTs refer to groups of individuals with interdependent tasks that can exert decision-making related to the scheduling of activities, work assignments and work methods [30, 42]. Rapid technological innovations, new forms of work arrangements and organizational disruption have made these challenges more pressing than ever and have led to the need to reexamine the underlying assumptions of job and team design that may no longer hold true [27, 37]. Indeed, scholars have called for more knowledge on how these changes challenge current organizational theories and research [7, 17].

It is increasingly common to organize distributed SMWTs that rely on electronic communication tools to plan and coordinate their work [16, 17]. This allows individual team members to be flexible in solving their work tasks, yet at the same time, team members may be highly interdependent in coordinating and completing the team's focal goals [18]. However, when a team is dependent on electronic communication, the group coupling structure, which refers to team members' interaction structure [38] may be weaker, making coordination more challenging. As such, for distributed team members, being self-managing and at the same time dependent on other team members for completing tasks can impose conflicting conditions for team members to coordinate.

In SMWTs, individual team members are collectively responsible for coordinating the team's work efforts efficiently [25, 49]. Despite coordination being considered key to team performance [2, 15], a recent review shows that research on SMWT effectiveness has been inconclusive and that we need more knowledge about the variables influencing SMWT performance [30]. Specifically, there appears to be a lack of empirical research examining how different types of team task interdependence affect coordination in distributed SMWTs.

In the current literature, there are several types of task interdependence [9]. While limited, research has shown that the level and types of task interdependence experienced by team members may affect outcomes differently [23, 43, 47]. We argue that in self-managing teams, individual team members' perceived coordination depend differentially on team members' perceptions of initiated and received task interdependence [21, 34].

To investigate this, we collected data from 110 individuals in 40 distributed teams in three organizations in Norway. Using multilevel analyses, we examined the moderating roles of initiated and received task interdependence on the relationship between teamlevel self-management and individual perceptions of coordination. By doing so, we aim to contribute to a better understanding of team dynamics with regard to 
how perceptions of self-management and task interdependence influence perceived coordination in distributed teams.

\section{Theory and hypotheses}

\subsection{Perceived coordination in distributed teams}

The concept of coordination, defined as the use of strategies and behavior patterns aimed at integrating and aligning the knowledge, actions and objectives of interdependent team members toward a common goal [41], has been central in management and organization theory. March and Simon [32] stressed that as long as there is more than one person in the organization, the degree of coordination among workers would largely influence their performance and organizational effectiveness. Studies in a wide range of settings have supported the idea that coordination is an important prerequisite for team performance outcomes [e.g., 2, 15, $33,40]$.

In recent years, distributed teams, where team members coordinate through computer-mediated communication tools, have gained massive popularity [17]. Despite the advantages of distributed teams, the reliance on computer-mediated communication places a greater demand on team members' self-management skills [23] and ability to recognize the level of task interdependence within the team [18]. Moreover, computer-mediated communication reduces the teams' ability to control communication processes, norms and behaviors [27], which in turn may be associated with increased coordination problems [20].

High degrees of self-management and individual autonomy are encouraged features of distributed teams $[23,29]$. However, distributed team members often have more difficulties coordinating among themselves compared to co-located teams due to the constraints imposed by electronic communication [18, 20]. For instance, a recent meta-analysis has demonstrated that trust, which in general is assumed to be more difficult to develop via computer-mediated communication, is important for distributed team interaction and coordination [3]. Due to the communicational constraints inherent in computer-mediated communication, distributed teams may thus experience greater challenges in developing a cohesive group coupling structure, which refers to the pattern of mutual relations between team members [38]. A weaker coupling structure could increase the difficulty in achieving good team coordination. However, although distributed, team members are still likely to be interdependent in carrying out their tasks. This makes them more dependent on each other, which in turn makes team intrapersonal connections and the coupling structure more important for achieving high-quality coordination [5].

\subsection{The role of self-management in coordination}

The notion of self-management stems from job and team design theories [37]. Self-management may be conceptualized as a feature of job design that represents the extent to which the job provides employees with discretion and control in deciding how to accomplish tasks [42]. The introduction of SMWTs stemmed from meeting challenges such as increased international competition, a changing workforce and rapidly changing environments [31]. In SMWTs, team members are expected to share leadership [see e.g., 10, 49] and to coordinate the work activities within the team, such as scheduling work activities, assigning work to each team member and monitoring their own performance [42]. Allowing the team such autonomy and flexibility will assumedly contribute to better coordination, increased team performance and overall effectiveness [2, 25, 42].

Despite the alleged benefits, there is a paradox inherent in self-management. As the level of selfmanagement increases, so does the interdependence and coordination requirements among team members $[25$, 27]. This potentially creates complex and more demanding work environments in which the individual team members coordinate.

In practice, SMWTs can be difficult to implement [33]. Naming a team as "self-managing" does not automatically mean that individual workers will take charge of their team functioning [33, 42]. While the team may be self-managing, individual team members need to balance complex work arrangements [27] and interdependencies with colleagues [25], as well as the larger organizational structures surrounding the team [33]. If not successfully implemented, SMWTs may actually decrease individuals' perceptions of any real self-involvement and autonomy [27]. Research on the unintended consequences of self-management has suggested that if improperly handled, high levels of selfmanagement can be associated with increased task conflict and reduced individual autonomy and intrapersonal trust $[25,26]$. A recent review of the SMWT literature also shows that SMWT may not always be effective, and that factors residing at the individual level (such as need for autonomy) and team level (such as task interdependence) may influence the effectiveness of SMWTs [30]. 


\subsection{Initiated and received task interdependence and consequences for coordination}

Among the different types of interdependence, task interdependence has been noted to be a desired characteristic for team coordination [2, 9]. Task interdependence can be defined as "the degree to which work is designed so that members depend upon one another for access to critical resources and create workflows that require coordinated action" [9, p. 5]. Task interdependence thus influences how team members interact. As such, task interdependence could serve to create a stronger coupling structure within the team, because the more team members need each other's input to do their work, the more they should need to interact [38]. High task interdependence has been listed among the team-level success factors for highperforming SMWTs [30]. Despite this, the role of task interdependence in relation to team coordination remains somewhat unclear or inconsistent $[2,10]$.

Research suggests there is a complex interplay between team self-management, task independence and performance [10]. For instance, work by Langfred [25, 26] suggest that trust within self-managing teams was lower when individual autonomy was high [26] but that low autonomy combined with low task interdependence was associated with high levels of team conflict [25]. Moreover, Rousseau and Aubé [42] found that SMWT effectiveness was contingent on task routineness, underscoring the importance of considering the role of the task. Finally, in a virtual team study [40], team performance was found to be better when task interdependence and team communication were aligned, suggesting that for distributed teams, the choice of communication technologies should be considered in relation to the nature of the task and the level of interdependence it creates.

Some conceptualizations of task interdependence have been categorized into two different types, namely initiated and received [21, 34, 47]. Initiated task interdependence refers to the extent to which work flows from a particular job to one or more other jobs. Received task interdependence, on the other hand, refers to the extent to which a particular job is affected by the workflow from other jobs [21, 34]. An individual may both initiate and receive work within the same team. Although all team members share the same overall objectives (i.e., the team's focal goal), each individual may often handle different portions of the task. As such, sometimes team members may perceive high levels of initiated task interdependence because they initiate the work of others, and at other times, they may depend on the completion of other team members' work, and perceive higher levels of received task interdependence.
Although the two types of task interdependence are related, they are conceptualized as unique task or job dimensions [21] and should therefore be differentially related to perceptions of coordination. However, currently only a few studies that have differentiated between the two forms of interdependence [12, 34, 47].

Initiated task interdependence encompasses a responsibility that the initiating team member feels toward other team members relying on his or her work [47]. Being depended upon can instill higher levels of self-efficacy [47] but also a need to meet expectations from others to act toward facilitating their work [12]. If the level of initiated task interdependence within a team is high, it could serve to tie team members more closely together [5]. As such, individuals initiating task interdependence should feel a motivation to facilitate other team members' work by engaging in more cooperative team behaviors. We expect that when the level of initiated interdependence within the team is high, team coordination is likely to be higher as the individual team members aim to facilitate each other's work. Therefore, we hypothesize:

H1: Initiated task interdependence positively moderates the positive relationship between team selfmanagement and perceived coordination such that the relationship is significantly more positive when initiated interdependence is high compared to when it is low.

In situations where a team member experiences received task interdependence, that is, perceives him or herself to be dependent on another team member to accomplish his or her work, the motivation for coordination may be different from employees initiating interdependence $[12,47]$. For instance, in the seminal work by Kiggundu [21] on initiated and received interdependence, he did not find the same positive motivational impact for received interdependence in comparison with initiated interdependence, such that received interdependence was negatively related to job involvement. He also found a negative but nonsignificant relationship between received interdependence and knowledge about results [21]. These findings imply that high levels of received interdependence may lead to less job involvement, and less engagement in overviewing the teams' strategies and behaviors toward attaining the common goal. As these are central features of coordination [41], we expect that the relationship between team self-management and perceived coordination would be more positive when individuals perceive the levels of received interdependence within the team as low compared to when it is high. Thus, we posit: 
H2: Received task interdependence negatively moderates the positive relationship between team selfmanagement and perceived coordination such that the relationship is significantly positive when received interdependence is low compared to when it is high.

\section{Figure 1. Conceptual model}

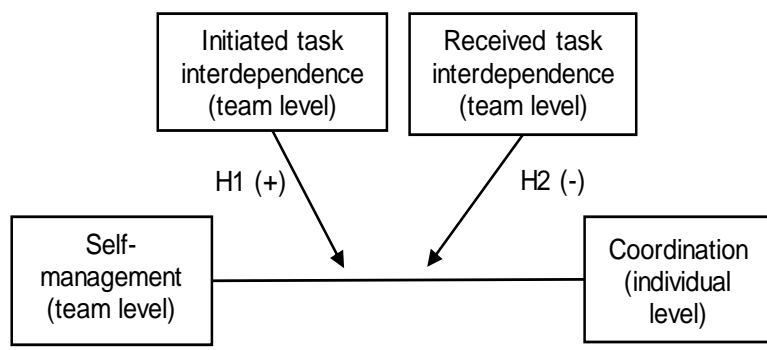

\section{Methodology}

\subsection{Sample}

Our sample consisted of 110 individuals in 40 teams from three different Norwegian organizations. A survey was sent out to 471 employees from different work units in the three organizations in the spring of 2017, of which 110 individuals $(23 \%)$ responded. Among these, 61 participants were employees of the first organization, 18 belonged to the second and 31 belonged to the third organization. In terms of demographics, 75 (68\%) were male, and 35 (32\%) were female. The average age was 41.7 years $($ s.d. $=9.5)$. The participants had an organizational tenure of 6.7 years $($ s.d. $=7.3)$ and tenure with their current leaders of $2.8(s . d .=2.9)$. Most of the participants held a bachelor's degree $(44.5 \%)$, followed by higher diploma (17.3\%), high school diploma $(17.3 \%)$, master's degree (14.5\%) and junior high school education $(6.4 \%)$.

The number of team members per team included in the analyses ranged from one to six. On average, there were 3.6 team members per team included in the analyses, which is representative of the team sizes in these organizations. All teams were distributed and worked together across geographically dispersed locations. To facilitate communication, the teams relied on electronic communication tools (i.e., e-mail, teleconferencing, and collaborative software) [16] to various degrees. The majority of them $(67.3 \%)$ said that they relied to a great extent $(5 / 5)$ on e-mail for communication in their daily work, while $29.1 \%$ had a moderate $(3 / 5)$ to high $(4 / 5)$ level of reliance. A total of $34.5 \%$ and $31.8 \%$ of participants said a high degree (4/5) of their daily work routine involved using videoconferencing and collaborative software, respectively, for communication, followed by $21.8 \%$ and $26.4 \%$ to a great extent $(5 / 5)$ and $25.5 \%$ and $22.7 \%$ to a moderate degree $(3 / 5)$. Overall, they demonstrated a relatively high extent of electronic dependence in interacting with others at work.

\subsection{Measures}

All constructs were measured using 7-point scales, and all measures used in this study were adopted from previous research. Before we tested the hypotheses, selfmanagement, initiated and received task interdependence were aggregated to team scores based on individual team members' ratings.

Self-management was measured using the three-item scale from the resistance to SMWTs measure [45]. These items have previously been used to measure resistance toward self-management by reversing the items. In the present study, we did not reverse the items, such that they reflect perceptions of the current degree of perceptions toward self-management within the team. A sample item is "Members of this team are eager to take on the responsibilities traditionally reserved for management." In the original study [45], the reverseitems scale had a Cronbach's alpha $(\alpha)$ of .72. In the present study, the non-reversed items had a reliability of .88 .

Initiated and received task interdependence were measured using two scales from Morgeson and Humphrey's [34]'s Work Design Questionnaire. Each scale consisted of three items. Sample items are "Others depend directly on my job" (initiated) and "My job cannot be done unless others do their work" (received). In our sample, the $\alpha$ 's of initiated interdependence and received interdependence were .90 and .88 , respectively, compared to .80 and .84 , as obtained by Morgeson and Humphrey [34].

Coordination was measured with five items from Lewis' [28] Transactive Memory System Scale $(\alpha=$ .78). Sample items include "Our team worked together in a well-coordinated fashion" and "We accomplished the tasks smoothly and efficiently." In our sample, the scale had an $\alpha$ of .82 .

Control variables. We controlled for demographic variables, including age, gender and education, as these could potentially account for variance in work-related assessments [48]. Further, as individuals with longer tenure may have attained job-related knowledge about their organization and leaders [36], we controlled for team members' organizational tenure and tenure with their leaders, as well as managerial responsibilities, measured in true numbers. We also controlled for employment fraction. Finally, we controlled for virtual work system alignment using a measure developed from Evans and Davis' [14]'s High Performance Work Systems scale and the degree of electronic dependence [16], rated from 1 (not at all) to 5 (a great extent), to 
ensure the variance nested in the wider work structure would be taken into account.

\subsection{Analytical procedures}

The predictor (self-management) and the two moderators (initiated and received task interdependence) in our study reside at the team level while the outcome variable resides at the individual level. This implies that the data are nested within a macro structure, i.e., members within the same team. Thus, there are potential shared variances among individual-rated measures due to non-independence [46] that could bias the standard error estimates. We therefore applied multilevel analyses [4] using IBM SPSS 25 to test the degree of interdependence within teams. To do so, we set team number as the level 2 unit, and team self-management, initiated and received task interdependence and coordination were set as the outcome variables to run the null hypothesis test without any predictors in the model. The intraclass correlations (ICC) were .18 for team coordination, .16 for team selfmanagement, .06 for initiated task interdependence, and .14 for received task interdependence. Overall, the intraclass correlation coefficients were relatively low, suggesting high amounts of variance within the teams. Theoretically, however, task interdependence is often discussed as a feature of job design [34, 37] that affects how team members interact collectively [see e.g., 22, 30]. Empirically, task interdependence has also been examined at the team level [e.g., 19, 24, 25, 43]. We thus proceeded to test our hypotheses using multilevel modeling in IBM SPSS 25 with maximum likelihood estimation.
Prior to testing the hypotheses, we centered the predictor variables (i.e., self-management, initiated and received task interdependence) using grand mean centering, which is the recommended option for variables at the team level $[13,35]$.

\section{Results}

Table 1 displays the means, standard deviations and reliability coefficients for the measures in this study. Hypothesis 1 proposes that initiated task interdependence would positively moderate the positive relationship between team self-management and perceived team coordination. We regressed perceived coordination on team self-management, initiated task interdependence and received task interdependence and their interaction terms together with the control variables. As is also shown in Table 2, all reported coefficients are unstandardized. The interaction between team self-management and initiated task interdependence was .41 and significant with a $p$-value of .009, as expected. We further assessed the simple slopes and plotted the relationships, as depicted in Figure 2, when initiated task interdependence was high versus when it was low [11].

The relationship between team self-management and perceived coordination was significantly positive $(.53, p$ $=.016$ ) when initiated task interdependence was high. However, the relationship turned negative, although not significant $(-.21, p=.222)$ when initiated task interdependence was low, as shown in Figure 2. Hypothesis 1 is thus supported.

Table 1. Descriptive Statistics, Correlations and Scale Reliabilities

\begin{tabular}{|c|c|c|c|c|c|c|c|c|c|c|c|c|c|c|c|}
\hline & Mean & $S D$ & 1 & 2 & 3 & 4 & 5 & 6 & 7 & 8 & 9 & 10 & 11 & 12 & 13 \\
\hline 1. Age & 41.7 & 9.5 & - & & & & & & & & & & & & \\
\hline 2. Gender & 1.32 & .47 & -.06 & - & & & & & & & & & & & \\
\hline 3. Education level & 3.44 & 1.13 & -.12 & .07 & - & & & & & & & & & & \\
\hline 4. Tenure & 6.67 & 7.33 & $.48^{* * *}$ & $.20^{*}$ & -.09 & & & & & & & & & & \\
\hline 5. Dyad tenure & 2.84 & 2.88 & .14 & -.12 & -.14 & .20 & - & & & & & & & & \\
\hline 6. Managerial responsibility & 1.66 & .48 & .15 & -.02 & -.08 & .08 & -.16 & & & & & & & & \\
\hline 7. Employment fraction & 1.02 & .19 & .00 & .14 & .05 & .05 & -.06 & .07 & - & & & & & & \\
\hline 8. Electronic dependence & 5.85 & .90 & .14 & $.21^{*}$ & $.21^{*}$ & .16 & -.17 & .02 & .05 & - & & & & & \\
\hline 9. VTWS alignment & 5.01 & .98 & .07 & .03 & .14 & $-.19^{\star}$ & -.03 & .04 & .00 & $.51^{* \star *}$ & - & & & & \\
\hline 10. Self-management ${ }^{a}$ & 5.15 & .77 & -.15 & -.05 & .11 & -.08 & -.15 & .14 & -.06 & .12 & $.22^{*}$ & $(.88)$ & & & \\
\hline 11. Initiated task interdependence ${ }^{a}$ & 4.70 & .90 & .01 & -.10 & -.05 & -.05 & -.10 & -.06 & -.00 & $.27^{* *}$ & $.22^{*}$ & $.25^{* \star *}$ & $(.90)$ & & \\
\hline 12. Received task interdependenc€ & $\epsilon 5.38$ & .81 & -.14 & -.15 & .02 & -.11 & .09 & -.03 & -.07 & .08 & .15 & -.02 & $.57^{* \star *}$ & $(.88)$ & \\
\hline 13. Coordination & 5.06 & 1.09 & -.03 & .08 & -.05 & .10 & .07 & -.14 & .05 & $.25^{\star *}$ & $.48^{* \star *}$ & $.20^{*}$ & $.31^{\star \star \star}$ & .02 & $(.82)$ \\
\hline
\end{tabular}

Note. Cronbach's alphas are displayed on the diagonal. $\mathrm{n}_{\text {indivudual }}=110, \mathrm{n}_{\text {team }}{ }^{*} p<.05^{* *} p<.01^{* * *} p<.001$.

${ }^{a}$ Team-level coefficients are shown. 
Figure 2. Two-way interaction between team self-management and team initiated task interdependence

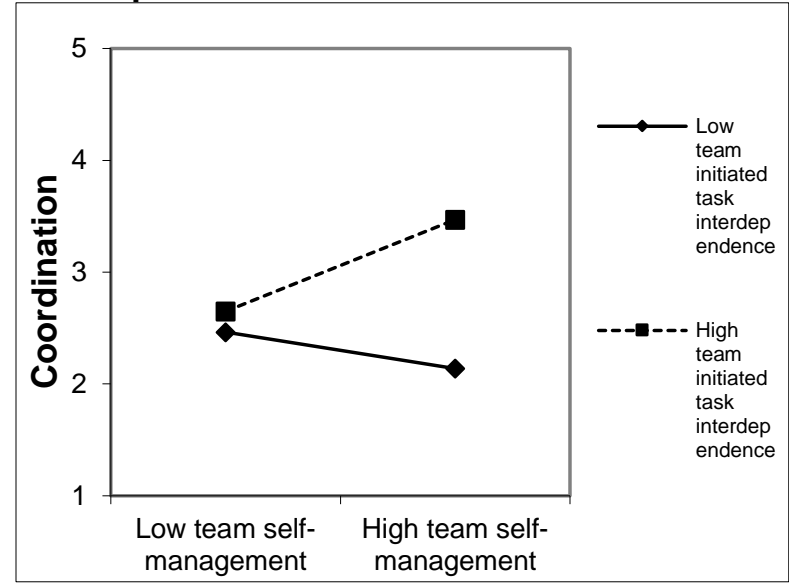

In contrast, Hypothesis 2 proposes that received task interdependence would negatively moderate the positive relationship between team self-management and perceived team coordination. As expected, the interaction between team self-management and received task interdependence was negative and significant (-.43, $p=.026)$. Further, the relationship between team selfmanagement and perceived coordination was significant and positive $(.51, p=.007)$ when received task interdependence was low. When received task interdependence was high, the relationship between team self-management and perceived coordination was negative, but nonsignificant $(-.19, p=.407)$, supporting Hypothesis 2. Figure 3 illustrates their interacted relationships.

\section{Figure 3. Two-way interaction between team self-management and team received task interdependence}

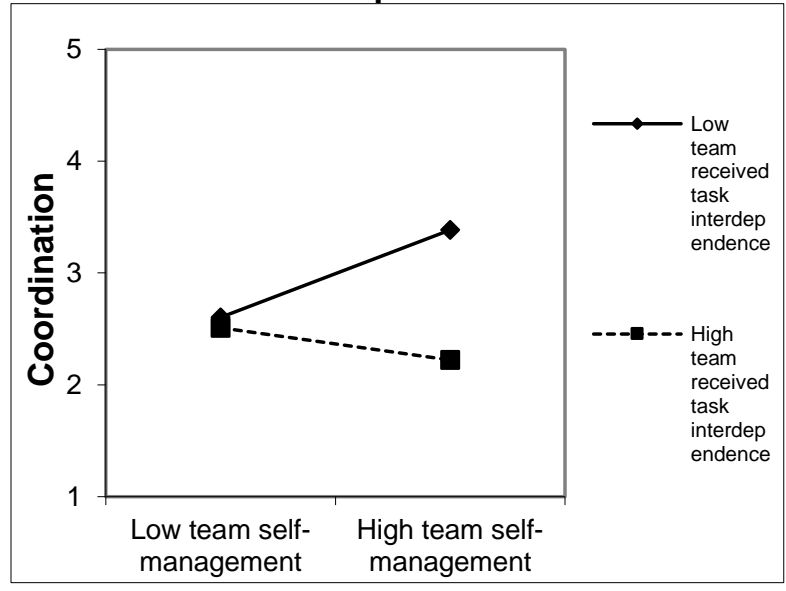

Because nine of the 40 teams in our sample were represented by one team member only, there is reason to question the reliability and validity of the multilevel analysis results. However, Clarke [6] suggested that multilevel models can generate valid fixed parameter and standard error estimates when there is a minimum of two or more subjects per cluster. We therefore performed additional analyses by removing the nine teams with only one member's response and reconducted our analyses including the remaining 31 teams with two or more team members $(n=101$, average members per team $=3.5$ ). The results with the reduced sample show that both the directions and strengths of the relationships remained similar to the results with the original sample. The interaction between team-level self-management and team-level initiated task interdependence (H1) turned out to be just above marginally significant $(.28, p=.116)$. The interaction of team-level self-management and team-level received task interdependence remained significant $(-.39, p=$ $.048)$.

\section{Discussion}

The present study examined the moderating roles of initiated and received task interdependence in the relationship between perceptions of self-management and coordination in distributed teams. Our results indicate that the level of team self-management was positively associated with perceived coordination when on the one hand, the level of initiated task interdependence was high (H1), and on the other hand, when the level of received task interdependence was low (H2). Thus, our findings suggest that initiated and received team task interdependence represent different team coupling structures that influence how team selfmanagement may facilitate $(\mathrm{H} 1)$, or hinder $(\mathrm{H} 2)$, team coordination.

\subsection{Theoretical implications}

Our results provide further insight into how team coupling structures, illustrated by their different types of task interdependence, may influence self-managing distributed team coordination. Such insights are important, given the need for more knowledge on team dynamics in distributed settings [7, 17]. In addition, as coordination is important for team efficiency and performance $[2,15]$, it is essential to build knowledge on the complexity between task interdependencies and their moderating role in the relationship between team self-management and coordination.

In particular, previous research has suggested that being a member of a SMWT does not necessarily mean that individual team members feel self-managing or autonomous [27] or that arranging a SMWT leads to 
self-coordinating team members [33]. Until now, the underlying coordinating mechanisms in distributed SMWTs have largely been unexplored. However, coordination has been suggested to be crucial for team performance in various settings [e.g., 2, 15]. The results presented in this study suggest that task interdependence may play a crucial role with respect to distributed SMWT coordination.

\section{Table 2. Regression Analyses and Slope} Difference Results

\begin{tabular}{|c|c|c|c|c|}
\hline \multirow{3}{*}{$\frac{\text { Variables }}{\text { Intercept }}$} & \multicolumn{4}{|c|}{ Coordination } \\
\hline & \multicolumn{2}{|c|}{ Model 1} & \multicolumn{2}{|c|}{ Model 2} \\
\hline & $2.50^{* *}$ & .88 & $2.68^{* *}$ & .87 \\
\hline Age & -.00 & .01 & -.00 & .01 \\
\hline Gender & -.32 & .21 & -.24 & .20 \\
\hline Education level & -.09 & .07 & -.10 & .08 \\
\hline Tenure & -.00 & .01 & -.00 & .01 \\
\hline Dyad tenure & .05 & .03 & .04 & .03 \\
\hline $\begin{array}{l}\text { Managerial } \\
\text { responsibility }\end{array}$ & .27 & .19 & .27 & .18 \\
\hline Employment fraction & .34 & .41 & .34 & .41 \\
\hline Electronic dependence & .06 & .11 & .01 & .11 \\
\hline VTWS alignment & $.47^{* * *}$ & .10 & $.48^{* * *}$ & .10 \\
\hline $\begin{array}{l}\text { Self-management } \\
(\mathrm{SM})^{\mathrm{a}}\end{array}$ & .15 & .15 & .16 & .14 \\
\hline $\begin{array}{l}\text { Initiated task } \\
\text { interdependence }(\mathrm{ITI})^{\mathrm{a}}\end{array}$ & & & $.42^{* *}$ & .15 \\
\hline $\begin{array}{l}\text { Received task } \\
\text { interdependence }(\mathrm{RTI})^{\mathrm{a}}\end{array}$ & & & $-.39^{* *}$ & .16 \\
\hline SMxITI & & & $.41^{* *}$ & .15 \\
\hline SMxRTI & & & $-.43^{*}$ & .15 \\
\hline Pseudo- $R^{2^{b}}$ & 0.31 & & 0.41 & \\
\hline$\Delta R^{2}$ & & & $.10^{* *}$ & \\
\hline Simple slopes & Gradi & & $t$-va & \\
\hline Low ITI & -0.21 & & $\begin{array}{l}-1.23 \\
\text { (n.s.) }\end{array}$ & \\
\hline High ITI & 0.53 & & $2.46^{*}$ & \\
\hline Low RTI & 0.51 & & $2.76^{* *}$ & \\
\hline High RTI & -0.19 & & $\begin{array}{l}-0.83 \\
(n . s .) \\
\end{array}$ & \\
\hline $\begin{array}{l}\text { Note. Unstandardized cc } \\
=110, n_{\text {team }}=40 .{ }^{*} p<.05 \\
\text { level coefficients are sho } \\
\text { (variance of full model } / \mathrm{v}\end{array}$ & ficient & . & $\begin{array}{l}\text { s } 1 \text { - } \\
\text { del). }\end{array}$ & \\
\hline
\end{tabular}

Our findings indicate that initiated and received task interdependence represent different team coupling structures $[12,47]$. When the distributed teams in our sample were highly self-managing, individual perceptions of coordination were higher when the level of initiated task interdependence was high and when the level of received task interdependence was low. This suggests that task interdependence as a whole may serve to tie distributed team members closer together by forming stronger intragroup couplings, resulting in increased contact and communication among team members $[5,38]$.

However, our findings suggest that the perceived value of the two types of task interdependence may not be equal. An interesting notion arising from this is whether initiated and received interdependence may represent competing interaction patterns when team members are experiencing more or less of the two types of task interdependence. For instance, when individuals are depended upon (that is, they initiate task interdependence), then may interact with their team members in different ways than if they are depending upon others (i.e., received task interdependence). In the former case, they may feel more effective and have a greater belief in the team's ability to perform its focal goals [47]. Further, the knowledge that they are depended upon by others may instill feelings of responsibility toward others $[12,47]$. The feelings of being responsible may foster their helping behaviors [43] and increase the frequency of communication with their fellow team members [40]. In an autonomous setting, such as in a distributed SMWT, both the felt responsibility for others and the increased interaction among team members may contribute to explaining why higher levels of team self-management were associated with higher levels of perceived coordination when initiated task interdependence was high.

In the latter case, individuals who perceive that they depend greatly on others are likely to feel powerless and that they have less information. These individuals might perceive that they rely on others to gain an overview of the team's overarching objectives. Consequently, they are more likely to be less engaged in the team [12, 21]. As such, high levels of received interdependence may be negative in terms of coordination outcomes, especially if the team is highly self-managing. Research in face-to-face settings suggests that higher levels of autonomy may be associated with increased task conflict and reduced trust in task-interdependent teams $[25,26]$. As such, balancing the level of task interdependencies to reduce the level of received task interdependence in distributed SMWTs may be important. Still, our understanding of the roles of these two types of task interdependence in distributed teams is currently limited. An interesting arena for future research is to further explore the role of task interdependence as competing coupling structures representing different interaction patterns.

While the success of SMWTs is certainly affected by factors at the individual, team and organizational level of analysis [30], one arena for future research is to continue the investigation of task interdependence in 
SMWT coordination. To better understand the interplay of initiated and received task interdependence, future research should continue to explore how these may relate differently to team dynamics. It would be interesting to further explore the two types of task interdependence in relation to self-efficacy, motivation and team performance in autonomous work teams relying on various collaborative technologies. Moreover, task interdependencies are not the only form of interdependence in need of further exploration. Another interesting avenue for future research would be to explore the role of task interdependencies in relation to other relevant interdependence constructs, such as technology interdependence [2, 43].

\subsection{Practical implications}

There are several benefits associated with organizing distributed SMWTs, such as increased flexibility and the opportunity to leverage individual team members' skills and competencies regardless of their geographical location [17, 42]. However, organizations and leaders seeking to reap the potential benefits of such teams need to be aware of the importance of different team task interdependencies.

Good information flow, sufficient levels of team communication and a focus on creating strong intragroup couplings within the team should all be potential ways of balancing the level of task interdependencies for optimal team coordination $[5,15$, 41]. However, as distributed teams may experience communicational challenges due to the reliance on computer-mediated communication [20,40], leaders of such teams should ensure that the team leverages these challenges for better coordination [18]. This could be done by encouraging face-to-face meetings when possible, providing the teams with rich media collaborative software, and conducting team-building activities [17, 20].

Moreover, when designing distributed SMWTs, managers should consider the team composition, as different individual dispositions could be related differently to self-management and shared leadership $[10,30]$, and to distributed teamwork [3, 23], but could also potentially lead to different reactions of initiated and received interdependence [47]. Last but not least, an issue to consider is whether the task interdependencies can be increased or reduced during the various phases of teamwork. Research suggests that high task interdependence may be more advantageous at earlier stages of teamwork, as it improves the connectedness among team members. On the other hand, it is costlier in terms of conflict and coordination requirements at later stages [18]. As such, organizations should not only consider the types of task interdependencies but also their timing when designing team processes.

\section{Limitations and concluding remarks}

Some limitations of the present research must be taken into account. First, the cross-sectional nature of the data does not allow us to assess causality and introduces the question of whether common method bias has affected our results [1, 44]. As such, we cannot refute reverse causality, or that there could be a bidirectional relationship between the variables. Experimental or longitudinal studies are needed in order to assess the causality of the proposed relationships and to reduce the threat of common method bias in our results [1].

Second, the construct measures in this study are perceptual. While more objective measures assessing the actual degree of self-management and task interdependence could have served to reduce the threat of common method bias, the choice of using perceptual measures was guided by an interest in capturing how these constructs are perceived by individual team members themselves [8]. In addition, the predictors and moderators (that is, self-management and the task interdependencies) were aggregated to the team level, while the outcome variable coordination was kept at the individual level. This may serve to reduce the threat of common method bias [39].

Third, the generalizability of our results is restricted by the relatively small sample size, which may limit the accuracy and stability of the estimates [44]. Moreover, as our sample consisted of employees from three Norwegian organizations, it does not allow us to generalize these results to other cultural contexts. The teams in our sample were dispersed across geographical locations, which serves to strengthen the external validity compared to research that focuses on a single organization and location [44]. Nevertheless, future research should replicate and extend our findings in a larger sample in different organizations and cultures to provide more evidence of generalizability.

As a concluding remark, the findings of this study contribute to highlighting the complexities of task interdependencies in distributed SMWTs, and make way for future research examining the roles of task interdependencies in contemporary team constellations. As the usage of distributed teams with high levels of self-management and autonomy continues to spread, gaining such insights is important, both for researchers and for practitioners seeking to optimize the working environment of individual team members and the overall team output in an increasingly volatile, digitized age. 


\section{References}

[1] Antonakis, J., Bendahan, S., Jacquart, P., and Lalive, R., "On making causal claims: A review and recommendations," The Leadership Quarterly, vol. 21, no. 6, pp. 1086-1120, 2010.

[2] Bailey, D. E., Leonardi, P. M., and Chong, J., "Minding the gaps: Understanding technology interdependence and coordination in knowledge work," Organization Science, vol. 21, no. 3, pp. 713-730, 2010.

[3] Breuer, C., Hüffmeier, J., and Hertel, G., "Does trust matter more in virtual teams? A meta-analysis of trust and team effectiveness considering virtuality and documentation as moderators," Journal of Applied Psychology, vol. 101, no. 8, pp. 1151-1177, 2016.

[4] Bryk, A. and Raudenbush, S. W., Hierarchical linear models: applications and data analysis methods. Newbury Park, CA: Sage, 1992.

[5] Burke, C. S., Stagl, K. C., Klein, C., Goodwin, G. F., Salas, E., and Halpin, S. M., "What type of leadership behaviors are functional in teams? A meta-analysis," The leadership quarterly, vol. 17, no. 3, pp. 288-307, 2006.

[6] Clarke, P., "Theory and methods: When can group level clustering be ignored? Multilevel models versus single-level models with sparse data," Journal of Epidemiology and Community Health (1979-), vol. 62, no. 8, pp. 752-758, 2008.

[7] Colbert, A., Yee, N., and George, G., "The Digital Workforce and the Workplace of the Future," Academy of Management Journal, vol. 59, no. 3, pp. 731-739, June 1, 20162016

[8] Conway, J. M. and Lance, C. E., "What reviewers should expect from authors regarding common method bias in organizational research," Journal of Business and Psychology, vol. 25, no. 3, pp. 325-334, 2010.

[9] Courtright, S. H., Thurgood, G. R., Stewart, G. L., and Pierotti, A. J., "Structural interdependence in teams: An integrative framework and meta-analysis," Journal of Applied Psychology, vol. 100, no. 6, pp. 1825-1846, 2015.

[10] D’Innocenzo, L., Mathieu, J. E., and Kukenberger, M. R., "A meta-analysis of different forms of shared leadershipteam performance relations," Journal of Management, vol. 42, no. 7, pp. 1964-1991, 2016.

[11] Dawson, J. F. and Richter, A. W., "Probing Three-Way Interactions in Moderated Multiple Regression: Development and Application of a Slope Difference Test," Journal of Applied Psychology, Article vol. 91, no. 4, pp. 917-926, 2006.

[12] Doerr, K. H., Freed, T., Mitchell, T. R., Schriesheim, C. A., and Zhou, X., "Work Flow Policy and Within-Worker and Between-Workers Variability in Performance," Journal of Applied Psychology, vol. 89, no. 5, pp. 911-921, 2004.

[13] Enders, C. K. and Tofighi, D., "Centering predictor variables in cross-sectional multilevel models: A new look at an old issue," Psychological Methods, vol. 12, no. 2, pp. 121138, 2007.

[14] Evans, W. R. and Davis, W. D., "High-Performance Work Systems and Organizational Performance: The Mediating Role of Internal Social Structure," Journal of Management, vol. 31, no. 5, pp. 758-775, 2005.

[15] Faraj, S. and Yan, X., "Coordination in Fast-Response Organizations," Management Science, Article vol. 52, no. 8, pp. 1155-1169, 2006.

[16] Gibson, C. B. and Gibbs, J. L., "Unpacking the Concept of Virtuality: The Effects of Geographic Dispersion, Electronic Dependence, Dynamic Structure, and National Diversity on Team Innovation," Administrative Science Quarterly, 10.2189/asqu.51.3.451 vol. 51, no. 3, pp. 451-495, 2006.

[17] Gilson, L. L., Maynard, M. T., Young, N. C. J., Vartiainen, M., and Hakonen, M., "Virtual Teams Research," Journal of Management, vol. 41, no. 5, pp. 1313-1337, 2015.

[18] Hertel, G., Geister, S., and Konradt, U., "Managing virtual teams: A review of current empirical research,"

Human Resource Management Review, vol. 15, no. 1, pp. 6995, 2005/03/01/ 2005.

[19] Hertel, G., Konradt, U., and Orlikowski, B., "Managing distance by interdependence: Goal setting, task interdependence, and team-based rewards in virtual teams," European Journal of work and organizational psychology, vol. 13, no. 1, pp. 1-28, 2004.

[20] Huang, R., Kahai, S., and Jestice, R., "The contingent effects of leadership on team collaboration in virtual teams," Computers in Human Behavior, vol. 26, no. 5, pp. 10981110, 2010.

[21] Kiggundu, M. N., "Task interdependence and job design: Test of a theory," Organizational Behavior and Human Performance, vol. 31, no. 2, pp. 145-172, 1983/04/01/ 1983.

[22] Kozlowski, S. W. J., Mak, S., and Chao, G. T., "TeamCentric Leadership: An Integrative Review," Annual Review of Organizational Psychology and Organizational Behavior, vol. 3, no. 1, pp. 21-54, 2016.

[23] Krumm, S., Kanthak, J., Hartmann, K., and Hertel, G., "What does it take to be a virtual team player? The knowledge, skills, abilities, and other characteristics required in virtual teams," Human Performance, vol. 29, no. 2, pp. 123-142, 2016/03/14 2016. 
[24] Langfred, C. W., "Autonomy and Performance in Teams: The Multilevel Moderating Effect of Task Interdependence," Journal of Management, vol. 31, no. 4, pp. 513-529, 2005.

[25] Langfred, C. W., "The Downside of Self-Management: A Longitudinal Study of the Effects tf Conflict on Trust, Autonomy, and Task Interdependence in Self-Managing Teams," Academy of Management Journal, vol. 50, no. 4, pp. 885-900, 2007.

[26] Langfred, C. W., "Too Much of a Good Thing? Negative Effects of High Trust and Individual Autonomy in Self-Managing Teams," Academy of Management Journal, vol. 47, no. 3, pp. 385-399, 2004.

[27] Langfred, C. W. and Rockmann, K. W., "The Push and Pull of Autonomy:The Tension Between Individual Autonomy and Organizational Control in Knowledge Work," Group \& Organization Management, vol. 41, no. 5, pp. 629657, 2016.

[28] Lewis, K., "Measuring transactive memory systems in the field: Scale development and validation," Journal of Applied Psychology, vol. 88, no. 4, pp. 587-604, 2003.

[29] Liao, C., "Leadership in virtual teams: A multilevel perspective," Human Resource Management Review, vol. 27, no. 4, pp. 648-659, 12// 2017.

[30] Magpili, N. C. and Pazos, P., "Self-Managing Team Performance: A Systematic Review of Multilevel Input Factors," Small Group Research, vol. 49, no. 1, pp. 3-33, 2018.

[31] Manz, C. C., "Self-Leading Work Teams: Moving Beyond Self-Management Myths," Human Relations, vol. 45, no. 11, pp. 1119-1140, 1992.

[32] March, J. G. and Simon, H. A., Organizations. New York: John Wiley \& Sons, 1966.

[33] Moe, N. B., Dingsøyr, T., and Dybå, T., "Overcoming barriers to self-management in software teams," IEEE software, vol. 26, no. 6, pp. 20-26, 2009.

[34] Morgeson, F. P. and Humphrey, S. E., "The Work Design Questionnaire (WDQ): Developing and validating a comprehensive measure for assessing job design and the nature of work," Journal of Applied Psychology, vol. 91, no. 6, pp. 1321-1339, 2006.

[35] Nezlek, J. B., "An Introduction to Multilevel Modeling for Social and Personality Psychology," Social and Personality Psychology Compass, vol. 2, no. 2, pp. 842-860, 2008.

[36] Ng, T. W. H. and Feldman, D. C., "Organizational tenure and job performance," Journal of Management, vol. 36 , no. 5, pp. 1220-1250, 2010.
[37] Oldham, G. R. and Hackman, J. R., "Not what it was and not what it will be: The future of job design research," Journal of Organizational Behavior, vol. 31, no. 2-3, pp. 463-479, 2010.

[38] Orton, J. D. and Weick, K. E., "Loosely coupled systems: A reconceptualization," Academy of management review, vol. 15, no. 2, pp. 203-223, 1990.

[39] Podsakoff, P. M., MacKenzie, S. B., Lee, J. Y., and Podsakoff, N. P., "Common method biases in behavioral research: A critical review of the literature and recommended remedies," Journal of Applied Psychology, vol. 88, no. 5, pp. 879-903, Oct 2003.

[40] Rico, R. and Cohen, S. G., "Effects of task interdependence and type of communication on performance in virtual teams," Journal of Managerial Psychology, vol. 20, no. 3/4, pp. 261-274, 2005.

[41] Rico, R., Sánchez-Manzanares, M., Gil, F., and Gibson, C., "Team Implicit Coordination Processes: A Team Knowledge-Based Approach," Academy of Management Review, vol. 33, no. 1, pp. 163-184, 2008.

[42] Rousseau, V. and Aubé, C., "Team Self-Managing Behaviors and Team Effectiveness: The Moderating Effect of Task Routineness," Group \& Organization Management, vol. 35, no. 6, pp. 751-781, 2010.

[43] Schoenherr, T., Bendoly, E., Bachrach, D. G., and Hood, A. C., "Task Interdependence Impacts on Reciprocity in IT Implementation Teams: Bringing Out the Worst in Us, or Driving Responsibility?," Production and Operations Management, vol. 26, no. 4, pp. 667-685, 2017.

[44] Shadish, W. R., Cook, T. D., and Campbell, D. T., Experimental and quasi-experimental designs for generalized causal inference. Wadsworth Cengage learning, 2002.

[45] Shapiro, D. L. and Kirkman, B. L., "Employees' reaction to the change to work teams: The influence of "anticipatory" injustice," Journal of Organizational Change Management, vol. 12, no. 1, pp. 51-67, 1999.

[46] Snijders, T. and Bosker, R., Multilevel analysis: an introduction to basic and advanced multilevel modeling, 2nd ed. Thousand Oaks, CA: Sage, 2012.

[47] Taggar, S. and Haines, V. Y., "I need you, you need me: a model of initiated task interdependence," Journal of Managerial Psychology, vol. 21, no. 3, pp. 211-230, 2006.

[48] Turban, D. B. and Jones, A. P., "Supervisor-subordinate similarity: Types, effects, and mechanisms," Journal of Applied Psychology, vol. 73, pp. 228-234, 1995.

[49] Wang, D., Waldman, D. A., and Zhang, Z., "A metaanalysis of shared leadership and team effectiveness," Journal of Applied Psychology, vol. 99, no. 2, pp. 181-198, 2014. 